\title{
ACCURACY OF MULTI-SLICE 3D-DOPPLER IN DIAGNOSIS OF MORBIDLY ADHERENT PLACENTA IN COMPARISON WITH 2D- DOPPLER
}

\author{
Walid E.M. Khalil; Mortada E.A. Abdel-Rahman; Omnia B.B Farag; and \\ Sahar M. A. Saber*
}

Obstetrics \& Gynaecology

Department, Faculty of Medicine

- Ain Shams University

Cairo, Egypt.

Corresponding author

Sahar M. A. Saber

Mobile: (+2) 01110065637

E.mail:

mandimoore71@yahoo.com

Received: $18 / 1 / 2021$

Accepted:8/2/2021

Online ISSN: 2735-3540

\begin{abstract}
:
Background: Morbidly adherent placenta can be diagnosed prenatally by different modalities. 2D, 3D multi-slice Doppler ultrasound and MRI have emerging roles in prenatal diagnosis of morbidly adherent placenta, but histopathological diagnosis is the gold standard.
\end{abstract}

Aim of the work: To detect the accuracy of multi-slice 3D Doppler ultrasound over 2D-Doppler in diagnosis of placenta accreta in relation to postpartum histopathology and intrapartum findings.

Patients and Methods: This study was conducted at Ain shams university maternity hospital during the period between March 2020 and September 2020. A total of 50 pregnant women having placenta Previa were included in the study. Patients were included in the study according to the following criteria: Pregnant women with history of previous cesarean section or hysterotomy, placenta previa with its lower edge covering the scar of previous cesarean section, From 28 wks - Full term.

Each patient was scanned in a systematic fashion by $2 D$ ultrasonography, 2D-Doppler, Multislice 3D-Doppler preoperatively and results were compared with histopathological examination postoperatively.

Results: Crowded vessels over peripheral sub-placental zone had the highest diagnostic characteristics among multislice 3D Doppler signs in diagnosis of placental invasion compared with postoperative histopathology with (sensitivity 95.2\%, specificity 93.1\%, PPV 90.9\%, NPV96.4\%, LR 270.00).

Hyper vascularity of serosa-bladder interface had the highest diagnostic characteristics among 2D Doppler ultrasonography signs in the diagnosis of placental invasion compared with postoperative histopathology with (sensitivity 90.5\%, specificity $89.7 \%$, PPV $86.4 \%$, NPV 92.9\%, LR 82.33).

Conclusion: Multi-slice 3D Doppler ultrasound is more accurate than 2D ultrasound in diagnosis of placenta accrete and degree of adherence in relation to postpartum histopathology and intrapartum findings.

Keywords: Morbidly adherent placenta; Multi-slice 3D-Doppler; 2D-Doppler

\section{INTRODUCTION:}

In women with placenta previa, the risk of placenta accreta varies from $2 \%$ in women younger than 35 years old with no previous caesarean section to $39 \%$ in women at or over 35 years of age with two or more 
caesarean sections. In the presence of these risk factors, the obstetrician must have a high index of suspicion for placenta accreta and take appropriate precautions ${ }^{(2,3)}$.

The three forms of morbidly adherent placenta (MAP): placenta accreta, increta and percreta, represent a significant obstetric challenge, at times resulting in lifethreatening bleeding, bladder injuries and/or peripartum hysterectomy. The increasing rate of cesarean section (CS) deliveries correlates with the rising incidence of $\mathrm{MAP}^{(5)}$.

This condition is often diagnosed during CS, upon placental removal, with unfavorable maternal outcome: attempts to remove the placenta can cause severe uterine bleeding. An accurate prenatal diagnosis is required to reduce the risk of maternal/fetal morbidity and mortality ${ }^{(6)}$.

3D multislice Doppler is a fastevolving imaging technique that holds a great potential for use in obstetrics and gynecology. Its sensitivity and specificity is reported to be close to $100 \%$ for diagnosing congenital uterine anomalies comparable with those of MRI \& laparoscopy, it can also be used for defining and mapping uterine lesions such as fibroids, adenomyosis, intrauterine synechia and initial evaluation of malignancy suspected patients, as well as artifacts in fetal heart scanning during second trimester ${ }^{(8)}$.

One area in which 3D-ultrasound seems to afford advantages over 2D ultrasound is in the imaging of abnormalities of the placenta, especially when the multislice capability of 3D ultrasound is combined with dynamic assessment of blood flow using power Doppler, considerable success had been found by using 3D multislice ultrasound imaging coupled with power Doppler in the imaging of patients with suspected morbid placentation $^{(9)}$.

\section{AIM OF THE STUDY:}

The purpose of this study was to detect accuracy of multislice 3D Doppler in comparison with 2D Doppler in diagnosis of placenta accreta and degree of adherence.

\section{PATIENTS AND METHODS:}

The present study was carried out at Ain Shams University Maternity Hospital during the period from March 2020 to September 2020. Women approached were recruited from Special Care Center of the fetus- Ain Shams University Maternity Hospital.

After proper counseling, all women who were chosen for enrollment agreed to participate.

Assuming sensitivity \& specificity of 2D Doppler accuracy of $81.8 \%$ \& $94.9 \%$ respectively compared to sensitivity \& specificity of 3D Doppler accuracy of 90.9 $\%$ \& $68.8 \%$ respectively based on previous study (Moniem et al., 2015); a sample size of 50 patients was enough to detect such figures of true, at 0.05 alpha $\& 0.80$ power of the test.

Patients were included in the study according to the following criteria: Pregnant lady with history of previous cesarean section or hysterotomy, placenta previa with its lower edge covering the scar of previous cesarean section, From 28 wks - Full term.

All patients underwent the following: History taking e.g. (Personal history, current problem / complaint (bleeding, pain), history of current pregnancy (details of the 1st, 2nd \& 3rd trimester), menstrual \& gynecological history, past obstetric history, past medical surgical history, drug History, family History); General examination; Local examination; and Investigations e.g., (complete blood picture (CBC), Rhesus factor (RH), Blood group and blood sugar, Urine for: glucose, protein and bacteruria, kidney function tests, liver functions tests. 
Ultrasound: It was carried out in the special care center of the fetus unit (Ain Shams University Maternity hospital). Apparatus used 4-7 MHZ Mulifrequency transabdominal convex transducer and VR59 three-dimensional endovaginal probe (Samsung WS80A Ultrasound machine)

For each patient, the whole placenta was scanned in a systematic fashion to determine whether those patients suspected of having advanced invasive morbid placentation. The placenta was imaged with a sufficient bladder volume to clearly visualize the serosa-bladder interface,

\section{D grayscale ultrasonography} criteria of morbidly adherent placenta: Loss of retroplacental sonolucent zone, Irregular retroplacental sonolucent zone, Thinning or disruption of the hyperechoic serosa-bladder interface, Presence of focal exophytic masses invading the urinary bladder, Abnormal placental lacunae

2D Doppler ultrasonography criteria of morbidly adherent placenta: Diffuse or focal lacunar flow, vascular lakes with turbulent flow, hypervascularity of serosabladder interface, markedly dilated vessels over peripheral subplacental zone

Multislice 3D Doppler ultrasonography: The multislice 3D mode allows simultaneous display of multiple sequential parallel views of a reference (sagittal, transverse or coronal) plane of an object. The reference plane, the number of images displayed within one screen $(1 \times 1,2$ $\times 1,3 \times 2,4 \times 3$ or $6 \times 4$ ), the orientation and rotation of an image, the magnitude of magnification and slice depth and interval ( 0.5 to $5 \mathrm{~mm}$ ) can be adjusted according to the region of interest (ROI), data set to create a cube that can be sliced and displayed in various ways using intuitive interfaces and the resulting data can be extracted along a flat plane ${ }^{(4)}$.

Criteria of Multislice 3D Doppler morbidly adherent placenta: Numerous coherent vessels involving the whole uterine serosa-bladder junction, Disruption of serosa bladder interface, Abnormal lacental lacunae

Decision making for the planned date of termination all were delivered by cesarean sections (Either elective at term (36-37 wks) or emergency in case of attack of antepartum hemorrhage).

Perioperative preparations: Preoperative CBC, Preoperative preparation of cross matched at least 4 units of packed RBCS, Counseling the patient and her family for the possibility of incidence of C.S hysterectomy, together with taking written high risk consent and consent for hysterectomy, At least 2 wide pore venous accesses were required, Senior obstetricians and anesthesiologists.

Operative Details: Either radical surgery in the form of cesarean hystrectomy was done or conservative surgery in the form of removal of the placenta with the adherent myometrium and reconstruction of the lower segment and hence either the whole uterus or part of myometrium was sent to histopathology for confirmation of the morbidly adherent placenta.

Operative findings of invasive morbid placentation were obtained from the obstetricians at the time of delivery and from histopathologic reports after either conservative surgery or cesarean hysterectomy.

Intraoperative signs suggestive of placental invasion was looked for and suspected by ${ }^{(2,4)}$ : Difficulty in placental separation and removal, Uncontrolled bleeding after placental separation in a wellcontracted uterus, Thinning of the lower uterine segment, Abnormal vasculature over the lower uterine segment.

Postoperative histopathological examination was done and compared with ultrasonongraphic findings. 
Statistical Methods: Demographic data of included women was presented as descriptive statistics (using range, mean and standard deviation for metric data, and range, median and interquartile range for discrete data). Demographic data, and outcomes of both groups were compared using t-test (for quantitative measures), and chi-squared and Fischer's Exact tests (for categorical measures). Microsoft ${ }^{\circledR}$ Excel $\AA$

Table (1): (version 2007) and SPSS $®$ for Windows $®$ version 16.0 were used for data presentation and statistical analysis.

\section{RESULTS:}

As regard the demographic data, 50 patients were included with mean age 29.6, BMI 28.1, gestational age $35.7 \&$ parity 3 as shown in table 1

\begin{tabular}{|l|l|lc|}
\hline \multicolumn{1}{|c|}{ Variables } & \multicolumn{1}{c|}{ Mean \pm SD } & \multicolumn{2}{c|}{ Range } \\
\hline Age (years) & $29.6 \pm 5.7$ & $20.0-42.0$ & \\
\hline BMI $\left(\mathrm{kg} / \mathrm{m}^{2}\right)$ & $28.1 \pm 2.4$ & $23.4-34.2$ & \\
\hline GA (week) & $35.8 \pm 1.2$ & $32.0-38.0$ & \multicolumn{2}{c|}{ Range } \\
\hline Median (1st-3rd IQ) & $3.0(2.0-3.3)$ & $1.0-4.0$ & \\
\hline Parity & &
\end{tabular}

Total=50. IQ: Interquartiles

Regarding diagnostic characteristics of 2D ultrasonography, 2D Doppler, multislice 3D Doppler among studied cases:

Loss of retroplacental sonolucent zone had the highest diagnostic characteristics among 2D ultrasonography signs in the diagnosis of placental invasion with sensitivity $90.5 \%$, specificity $69 \%$, PPV $67.9 \%$, NPV $90.9 \%$ as shown in table 2 .

While hypervascularity of serosabladder interface had the highest diagnostic characteristics among 2D Doppler ultrasonography signs in the diagnosis of placental invasion with sensitivity $85.7 \%$ \& specificity $69 \%$, PPV $68.4 \%$, NPV $92.9 \%$ as shown in table 3.

Crowded vessels over peripheral subplacental zone had the highest diagnostic characteristics among multislice 3D Doppler signs in the diagnosis of placental invasion with sensitivity $95.2 \% \quad \& \quad$ specificity 93.1\%,PPV 90.9\%, NPV $96.4 \%$ as shown in table 4 . 
Table (2): Diagnostic characteristics of 2D Ultrasonography in the diagnosis of placental invasion:

\begin{tabular}{|c|c|c|c|c|c|c|}
\hline \multirow[t]{2}{*}{ Characters } & Value & $95 \% \mathrm{CI}$ & Value & $95 \% \mathrm{CI}$ & Value & $95 \% \mathrm{CI}$ \\
\hline & \multicolumn{2}{|c|}{ Loss of retroplacental zone } & \multicolumn{2}{|c|}{ Irregular retroplacental zone } & \multicolumn{2}{|c|}{$\begin{array}{c}\text { Disruption of bladder } \\
\text { interface }\end{array}$} \\
\hline Sensitivity & $90.5 \%$ & $69.6 \%-98.8 \%$ & $66.7 \%$ & $43.0 \%-85.4 \%$ & $57.1 \%$ & $34.0 \%-78.2 \%$ \\
\hline Specificity & $69.0 \%$ & $49.2 \%-84.7 \%$ & $58.6 \%$ & $38.9 \%-76.5 \%$ & $93.1 \%$ & $77.2 \%-99.2 \%$ \\
\hline DA & $78.0 \%$ & $64.0 \%-88.5 \%$ & $62.0 \%$ & $47.2 \%-75.3 \%$ & $78.0 \%$ & $64.0 \%-88.5 \%$ \\
\hline YI & $59.4 \%$ & $38.4 \%-80.4 \%$ & $25.3 \%$ & $1.7 \%-52.3 \%$ & $50.2 \%$ & $27.2 \%-73.3 \%$ \\
\hline PPV & $67.9 \%$ & $47.6 \%-84.1 \%$ & $53.8 \%$ & $33.4 \%-73.4 \%$ & $85.7 \%$ & $57.2 \%-98.2 \%$ \\
\hline NPV & $90.9 \%$ & $70.8 \%-98.9 \%$ & $70.8 \%$ & $48.9 \%-87.4 \%$ & $75.0 \%$ & $57.8 \%-87.9 \%$ \\
\hline $\mathrm{LR}+$ & 2.92 & $1.67-5.10$ & 1.61 & $0.95-2.73$ & 8.29 & $2.07-33.19$ \\
\hline LR- & 0.14 & $0.04-0.53$ & 0.57 & $0.29-1.12$ & 0.46 & $0.28-0.76$ \\
\hline \multirow[t]{2}{*}{ LR } & 21.11 & $4.03-110.57$ & 2.83 & $0.88-9.13$ & 18.00 & $3.37-96.22$ \\
\hline & \multicolumn{2}{|c|}{ Mass invading the bladder } & \multicolumn{2}{|c|}{ Abnormal placental lacunar } & & \\
\hline Sensitivity & $42.9 \%$ & $21.8 \%-66.0 \%$ & $66.7 \%$ & $43.0 \%-85.4 \%$ & & \\
\hline Specificity & $96.6 \%$ & $82.2 \%-99.9 \%$ & $34.5 \%$ & $17.9 \%-54.3 \%$ & & \\
\hline DA & $74.0 \%$ & $59.7 \%-85.4 \%$ & $48.0 \%$ & $33.7 \%-62.6 \%$ & & \\
\hline YI & $39.4 \%$ & $17.2 \%-61.6 \%$ & $1.1 \%$ & $25.4 \%-27.7 \%$ & & \\
\hline PPV & $90.0 \%$ & $55.5 \%-99.7 \%$ & $42.4 \%$ & $25.5 \%-60.8 \%$ & & \\
\hline NPV & $70.0 \%$ & $53.5 \%-83.4 \%$ & $58.8 \%$ & $32.9 \%-81.6 \%$ & & \\
\hline $\mathrm{LR}+$ & 12.43 & $1.70-90.76$ & 1.02 & $0.68-1.52$ & & \\
\hline LR- & 0.59 & $0.41-0.86$ & 0.97 & $0.44-2.12$ & & \\
\hline LR & 21.00 & $2.39-184.63$ & 1.05 & $0.32-3.45$ & & \\
\hline
\end{tabular}

CI: Confidence interval, DA: Diagnostic accuracy, PPV: Positive Predictive value, NPV: Negative Predictive value,

LR+: Positive likelihood ratio, LR-: Negative likelihood ratio, LR: Diagnostic odd ratio

Table (3): Diagnostic characteristics of 2D Doppler ultrasonography in the diagnois of placental invasion:

\begin{tabular}{|c|c|c|c|c|}
\hline & \multicolumn{2}{|c|}{ Diffuse or focal lacunar flow } & \multicolumn{2}{|c|}{ Vascular lakes with turbulent flow } \\
\hline & Value & $95 \% \mathrm{CI}$ & Value & $95 \% \mathrm{CI}$ \\
\hline Sensitivity & $85.7 \%$ & $63.7 \%-97.0 \%$ & $81.0 \%$ & $58.1 \%-94.6 \%$ \\
\hline Specificity & $69.0 \%$ & $49.2 \%-84.7 \%$ & $69.0 \%$ & $49.2 \%-84.7 \%$ \\
\hline $\mathrm{DA}$ & $76.0 \%$ & $61.8 \%-86.9 \%$ & $74.0 \%$ & $59.7 \%-85.4 \%$ \\
\hline YI & $54.7 \%$ & $32.2 \%-77.2 \%$ & $49.9 \%$ & $26.1 \%-73.7 \%$ \\
\hline PPV & $66.7 \%$ & $46.0 \%-83.5 \%$ & $65.4 \%$ & $44.3 \%-82.8 \%$ \\
\hline NPV & $87.0 \%$ & $66.4 \%-97.2 \%$ & $83.3 \%$ & $62.6 \%-95.3 \%$ \\
\hline LR+ & 2.76 & $1.56-4.88$ & 2.61 & $1.46-4.66$ \\
\hline LR- & 0.21 & $0.07-0.61$ & 0.28 & $0.11-0.69$ \\
\hline \multirow[t]{3}{*}{ LR } & 13.33 & $3.12-57.04$ & 9.44 & $2.46-36.20$ \\
\hline & \multicolumn{2}{|c|}{ Hypervascularity of serosa-bladder interface } & \multicolumn{2}{|c|}{$\begin{array}{l}\text { Markedly dilated vessels over } \\
\text { peripheral subplacental zone }\end{array}$} \\
\hline & Value & $95 \% \mathrm{CI}$ & Value & $95 \% \mathrm{CI}$ \\
\hline Sensitivity & $90.5 \%$ & $69.6 \%-98.8 \%$ & $71.4 \%$ & $47.8 \%-88.7 \%$ \\
\hline Specificity & $89.7 \%$ & $72.6 \%-97.8 \%$ & $48.3 \%$ & $29.4 \%-67.5 \%$ \\
\hline DA & $90.0 \%$ & $78.2 \%-96.7 \%$ & $58.0 \%$ & $43.2 \%-71.8 \%$ \\
\hline YI & $80.1 \%$ & $63.4 \%-96.9 \%$ & $19.7 \%$ & $6.8 \%-46.2 \%$ \\
\hline PPV & $86.4 \%$ & $65.1 \%-97.1 \%$ & $50.0 \%$ & $31.3 \%-68.7 \%$ \\
\hline NPV & $92.9 \%$ & $76.5 \%-99.1 \%$ & $70.0 \%$ & $45.7 \%-88.1 \%$ \\
\hline LR+ & 8.75 & $2.97-25.76$ & 1.38 & $0.89-2.15$ \\
\hline LR- & 0.11 & $0.03-0.40$ & 0.59 & $0.27-1.28$ \\
\hline LR & 82.33 & $12.51-541.98$ & 2.33 & $0.71-7.70$ \\
\hline
\end{tabular}


CI: Confidence interval, YI: Youden's index, DA: Diagnostic accuracy, PPV: Positive Predictive value, NPV: Negative Predictive value, LR+: Positive likelihood ratio, LR-: Negative likelihood ratio, LR: Diagnostic odd ratio

Table (4): Diagnostic characteristics of multislice 3D Doppler in the diagnois of placental invasion

\begin{tabular}{|l|c|c|c|c|c|c|}
\hline \multirow{2}{*}{ Characters } & Value & $95 \%$ CI & Value & $95 \%$ CI & Value & $95 \%$ CI \\
\cline { 2 - 7 } & \multicolumn{2}{|c|}{$\begin{array}{c}\text { Crowded vessels over peripheral } \\
\text { sub-placental zone }\end{array}$} & $\begin{array}{c}\text { Disruption of the bladder } \\
\text { interface }\end{array}$ & \multicolumn{2}{|c|}{$\begin{array}{c}\text { Abnormal placental } \\
\text { lacunae }\end{array}$} \\
\hline Sensitivity & $95.2 \%$ & $76.2 \%-99.9 \%$ & $85.7 \%$ & $63.7 \%-97.0 \%$ & $76.2 \%$ & $\begin{array}{c}52.8 \%- \\
91.8 \%\end{array}$ \\
\hline Specificity & $93.1 \%$ & $77.2 \%-99.2 \%$ & $89.7 \%$ & $72.6 \%-97.8 \%$ & $55.2 \%$ & $\begin{array}{c}35.7 \%- \\
73.6 \%\end{array}$ \\
\hline DA & $94.0 \%$ & $83.5 \%-98.7 \%$ & $88.0 \%$ & $75.7 \%-95.5 \%$ & $64.0 \%$ & $\begin{array}{c}49.2 \%- \\
77.1 \%\end{array}$ \\
\hline YI & $88.3 \%$ & $75.4 \%-100 \%$ & $75.4 \%$ & $56.7 \%-94.0 \%$ & $31.4 \%$ & $5.7 \%-57.0 \%$ \\
\hline PPV & $90.9 \%$ & $70.8 \%-98.9 \%$ & $85.7 \%$ & $63.7 \%-97.0 \%$ & $55.2 \%$ & $35.7 \%-$ \\
\hline NPV & $96.4 \%$ & $81.7 \%-99.9 \%$ & $89.7 \%$ & $72.6 \%-97.8 \%$ & $76.2 \%$ & $\begin{array}{c}52.8 \%- \\
91.8 \%\end{array}$ \\
\hline LR+ & 13.81 & $3.61-52.77$ & 8.29 & $2.80-24.54$ & 1.70 & $1.06-2.72$ \\
\hline LR- & 0.05 & $0.01-0.35$ & 0.16 & $0.06-0.46$ & 0.43 & $0.19-0.99$ \\
\hline LR & 270.00 & $22.86-3189.2$ & 52.00 & $9.41-287.34$ & 3.94 & $1.14-13.64$ \\
\hline
\end{tabular}

CI: Confidence interval, DA: Diagnostic accuracy, PPV: Positive Predictive value, NPV: Negative Predictive value, LR+: Positive likelihood ratio, LR-: Negative likelihood ratio, LR: Diagnostic odd ratio

\section{DISCUSSION:}

The current study showed that there were no significant differences according to placental invasion (invasion $=21 \&$ no invasion $=29$ ) regarding age, BMI, and GA $(p=0.085,0.256$, and 0.061). There was significant difference regarding parity $(\mathrm{p}<0.001)$.

In this matched studies, Fathy et al. ${ }^{(10)}$ study agreed with current study and stated that age, BMI, and GA had no significant difference, But disagreed regarding parity with current study and stated that parity had no significant difference. While D'Antonio et al. ${ }^{(11)}$ study agreed with current study regarding parity \& concluded that the incidence of abnormal invasive placentation (AIP) increased in the past decades as a consequence of increasing caesarean section rates. As well; Guleria et al. (12) study concluded that the risk factors of abnormal invasive placentation (AIP) were placenta previa and a past history of cesarean delivery. On the other hand, Wright et al. ${ }^{(13)}$ study agreed with current study and stated that there was no significant relation between degree of placental invasion, and massive blood loss, But disagreed regarding parity and stated that there was no significant relation between parity and massive blood loss, and Thia et al. (14) study concluded that the depth of invasion in MAP is increased with multiple previous surgeries or excessive curettage or infection causing defective decidua basalis.

Agreement between 2D and placental invasion, Loss of retro-placental sono-lucent zone and hyper-vascularity of serosa bladder interface had the highest diagnostic 
characteristics among 2D ultrasonography signs in the diagnosis of placental invasion with sensitivity and specificity $90.5 \%$, $69.0 \%$ and $90.5 \%, 89.7 \%$ respectively.

There was significant moderate agreement to loss of retro-placental sonolucent zone, thinning or disruption of the hyperechoic serosa-bladder interface, focal exophytic mass invading the bladder ( $p$ $<0.001$ ) and non-significant low agreement to irregular retro-placental sono-lucent zone, abnormal placental lacunar ( $\mathrm{p}=0.077$ and 0.933).

Moniem et al. ${ }^{(15)}$ study agreed with current study and stated that the best 2D grayscale ultrasound parameter for the detection of difficult placental separation and considerable intraoperative blood loss was loss of the retroplacental sonolucent zone (74.2\% NPV). In addition, the best 2D gray-scale ultrasound parameters for the detection of emergency hysterectomy in the subjects were disruption of the hyperechoic uterine serosa-bladder interface (81.8\% sensitivity) and exophytic mass invading the bladder $(94.9 \%$ specificity, $66.7 \%$ PPV, and $84.1 \%$ NPV).

In addition, Shi et al. ${ }^{(16)}$ study found that the most prominent grayscale sign to diagnose placenta accreta was dilated vessels extending from the placenta to the myometrium.

Wong et al. (17) study agreed with current study and concluded that the loss of the placental-uterine interface and the presence of abnormal vessels crossing this interface were the most specific criteria to diagnose MAP using $2 \mathrm{D}$ gray-scale ultrasound scan.

Japaraj et al. (18) study agreed with current study and found that the prominent gray-scale ultrasound sign to diagnose placenta accreta was dilated vessels extending from the placenta to myometrium, and the most prominent color Doppler sign to diagnose placenta accrete was abnormal vessels connecting the placenta to bladder.
Comstock et al. ${ }^{(19)}$ study diagreed with current study \& found that the absence of the space between the placenta and myometrium is not a diagnostic sign for MAP because the space may be normally absent without MAP. They recommended the use of the color Doppler to identify placental sinuses crossing the uterine wall to the bladder.

Regarding agreement between 2D Doppler and placental invasion there was significant high agreement to diffuse or focal lacunar flow and markedly dilated vessels over peripheral sub-placental zone; ( $p<0.001$ ), significant moderate agreement to vascular lakes with turbulent flow; ( $\mathrm{p}<0.001$ ) and nonsignificant low agreement to hyper-vascularity of serosa-bladder interface; $(\mathrm{p}=<0.001)$.

Hussein et al. ${ }^{(20)}$ stated that regarding 2D color Doppler can increase the accuracy of prediction of massive hemorrhage in cases of PAS disorders and only the presence of numerous coherent vessels involving the bladder-serosal interface $(\mathrm{p}=$ 0.002) was proven to be independent predictor of major hemorrhage during hysterectomy which is due to different inclusion and exclusion criteria than current study.

Also, Shi et al. ${ }^{(16)}$, Japaraj et al. ${ }^{(18)}$ studies found that the most prominent color Doppler diagnostic sign was the presence of abnormal vessels connecting the placenta to the bladder which is due to different methodology than current study.

Regarding agreement between multislice 3D Doppler and placental invasion, crowded vessels over peripheral sub-placental zone had the highest diagnostic characteristics among multi-slice 3D Doppler signs in the diagnosis of placental invasion with sensitivity and specificity $95.2 \%$ and $93.1 \%$.

There was significant high agreement between multi-slice 3D Doppler regarding disruption of serosa bladder interface) and placental invasion; ( $p<0.001)$, significant 
low agreement between multi-slice 3D Doppler regarding abnormal placental lacunae and placental invasion; $(\mathrm{p}=0.027)$ and non-significant high agreement between multi-slice 3D Doppler regarding numerous coherent vessels involving the whole uterine serosa-bladder junction and placental invasion; $(\mathrm{p}=0.160)$.

Moniem et al. ${ }^{(21)}$ study agreed with us and stated that the 3D MSV Doppler is a useful adjunctive tool to the 3D power Doppler or color Doppler to refine the diagnosis of MAP. The 3D MSV Doppler increased the accuracy and predictive values of the diagnostic criteria of MAP compared with the 3D power Doppler. The sensitivity and negative predictive value (NPV) $(79.6 \%$ and $82.2 \%$, respectively) of crowded vessels over the peripheral sub-placental zone to detect difficult placental separation and considerable intraoperative blood loss in cases of MAP using the 3D power Doppler was increased to $82.6 \%$ and $84 \%$, respectively, using the 3D MSV Doppler. In addition, the sensitivity, specificity, and positive predictive value (PPV) (90.9\%, $68.8 \%$, and $47 \%$, respectively) of the disruption of the uterine serosa-bladder interface for the detection of emergency hysterectomy in cases of MAP using the 3D power Doppler was increased to $100 \%$, $71.8 \%$, and $50 \%$, respectively, using the 3D MSV Doppler.

Silver et al. ${ }^{(22)}$ study agreed with us and stated that one area in which 3D ultra-sound seems to afford advantages over 2D ultrasound is in the imaging of abnormalities of the placenta, especially when the multislice capability of 3D ultrasound is combined with dynamic assessment of blood flow using power Doppler.

The current study showed that multislice 3D Doppler ultrasound is more accurate than 2D ultrasound in diagnosis of placenta accrete and degree of adherence in relation to postpartum histopathology and intrapartum findings.

\section{Conclusion}

Multi-slice 3D Doppler ultrasound is more accurate than 2D ultrasound in diagnosis of placenta accreta and degree of adherence in relation to postpartum histopathology and intrapartum findings.

\section{REFERENCES:}

1. Batieha AM, Al-Daradkah SA, Khader YS, Basha A, Sabet F, Athamneh TZ (2017): Cesarean section: incidence, causes, associated factors and outcomes: a National Prospective Study from Jordan. Gynecol Obstet Case Rep; 3(3):55.

2. Wu S, Kocherginsky M, Hibbard JU (2005): Abnormal placentation: Twentyyear analysis. Am J Obstet Gynecol; 192: 14581461.

3. Chou MM, Chen WC, Tseng JJ, Chen YF, Yeh TT, Ho ES (2009): Prenatal detection of bladder wall involvement in invasive placentation with sequential twoDimensional and adjunctive threeDimensional Ultrasonography. Taiwan J Obstet Gynecol; 48: 38-45.

4. Silver RM and Barbour KD (2015): Placenta accreta spectrum: accreta, increta, and percreta. Obstet Gynecol Clin; 42(2): 381-402.

5. Wortman AC and Alexander JM (2013): Placenta accreta, increta, and percreta. Obstet Gynecol Clin; 40(1): 137-54.

6. Tikkanen M, Paavonen J, Loukovaara M, Stefanovic V (2011): Antenatal diagnosis of placenta accreta leads to reduced blood loss. Acta Obstet gynecol scand; 90(10): 1140-6.

7. Sharma S, Singh C, Verma S, Rastogi H, Kaul A (2017): Prenatal diagnosis and management of morbidly adherent placenta. J Clin Diag Res; 11(2): QJ01.

8. Chan YY, Jayaprakasan K, Zamora J, Thornton JG, Raine-Fenning N, Coomarasamy A (2011): The prevalence of congenital uterine anomalies in unselected and high-risk populations: a systematic review. Hum reprod update; 17(6):761-71. 
9. Chou MM, Tseng JJ, Ho ES, Hwang JI (2001): Three dimensional Colour power Doppler imaging in the assessment of uteroplacental neovascularization in placenta previa increta/percreta. Am J Obstet Gynecol; 185: 1257-1260.

10. Fathy HM, Bahaa AM, Alanwar AA, Koura AMS (2018): Accuracy of the threedimensional 3D Doppler over conventional 2D ultrasound in the diagnosis of morbid adherent placenta (MAP). EBWHJ; 8(4):300-305.

11. D'Antonio F and Bhide A (2014): Ultrasound in placental disorders. Best Pract Res Clin Obstet Gynaecol; 28: 42942.

12. Guleria K, Gupta B, Agarwal S, Suneja A, Vaid N, Jain S (2013): Abnormally invasive placenta: changing trends in diagnosis and management. Acta Obstet Gynecol Scand; 92: 461-4.

13. Wright JD, Pri-Paz S, Herzog TJ, Shah M, Bonanno C, Lewin SN, Simpson LL, Gaddipati S, Sun X, D'Alton ME, Devine P (2011): Predictors of massive blood loss in women with placenta accreta. Am J obstet gyneco; 205(1): 38-e1.

14. Thia EW, Lee SL, Tan HK, Tan LK (2007): Ultrasonographical features of morbidlyadherent placentas. Singapore Med J; 48: 799-802.

15. Moniem AM, Abdelazim IA, Khalifa AA, Fahmy AA, Rabei NH (2016): Accuracy of Gray-scale and Three-dimensional Power Doppler Ultrasound Parameters in the Diagnosis of Morbidly Adherent Placenta. J Bas Clin Reprod Sci; 5(1): 12-20.
16. Shi H, Pi P, Ding Y (2012): Diagnosis of placenta previa accreta by two dimensional ultrasonography and color doppler in patients with cesarean section. Zhong nan da xue xue bao. Yi xue ban= Journal of Central South University. Medical sciences 2012; 37(9):939-43.

17. Wong HS, Zuccollo J, Tait J, Pringle K (2008): Antenatal topographical assessment of placenta accreta with Ultrasound. Aust N Z J Obstet Gynaecol; 48: 421-43.

18. Japaraj RP, Mimin TS, Mukudan K (2007): Antenatal diagnosis of placenta previa accreta in patients with previous cesarean scar. J Obstet Gynaecol Res; 33: 431-7.

19. Comstock CH, Love JJ Jr, Bronsteen RA, Lee W, Vettraino IM, Huang RR, Lorenz RP (2004): Sonographic detection of placenta accreta in the second and third trimesters of pregnancy. Am J Obstet Gynecol; 190: 1135-40.

20. Hussein AM, Momtaz M, Elsheikhah A, Abdelbar A, Kamel A (2020): The role of ultrasound in prediction of intra-operative blood loss in cases of placenta accreta spectrum disorders. Arch of Gynecol Obstet; 1:1-8.

21. Moniem AM, Ibrahim A, Akl SA, AboulEnen L, Abdelazim IA (2015): Accuracy of three-dimensional multislice view Doppler in diagnosis of morbid adherent placenta. $\mathbf{J}$ Turk Ger Gynecol Assoc; 16(3):126.

22. Silver RM, Landon MB, Rouse DJ (2006): Maternal morbidity associated with multiple repeat cesarean deliveries. Obstet Gynecol; 107:1226-1232. 


\section{Walid E.M. Khalil, et al.,}

دقة الفحص بدوبلر متعدد الشرائح ثلاثي الأبعاد عن دوبلر ثنائي الأبعاد في تثخيص المشيمة اللصيقة بشكل مرضي

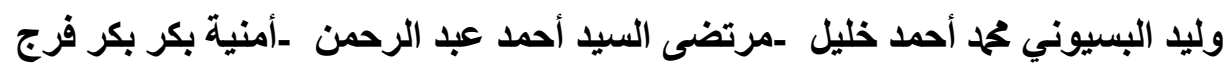

-سهر محمد عبد المقصود محمد صابر

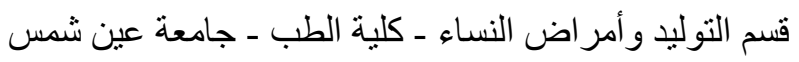

الخلفية: تُمثل عملية الولادة القيصرية عملية إنقاذ مهمة لحياة الأم والطفل، وقد زاد اللجوء إليها بشكل كبير خلال

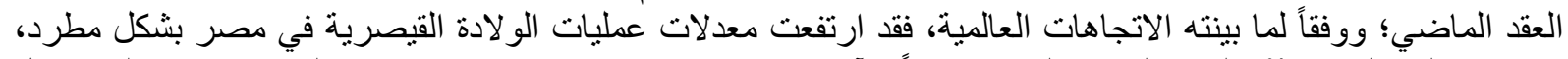

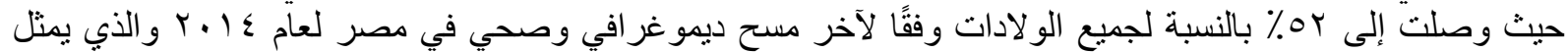

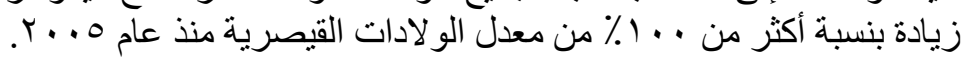

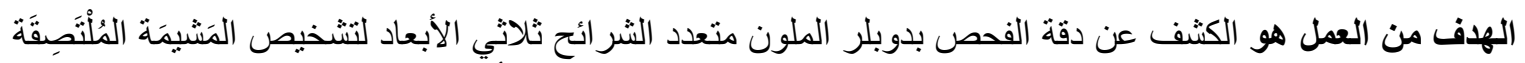

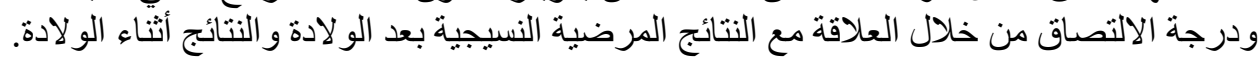

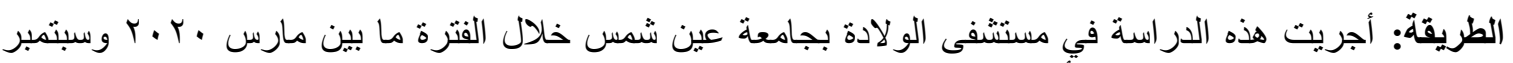

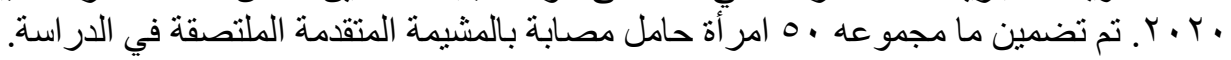

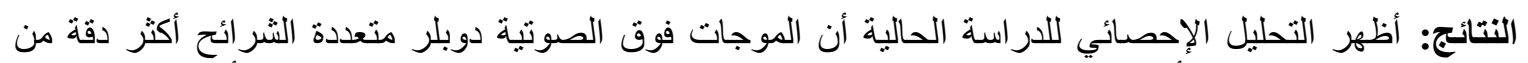
الموجات فوق الصوتية ثنائية الأبعاد في تشخيص المشيمة الملتصقة ودرجة الالتزام فيما يتعلق بتشريح الأنسجة بعد الو لادة

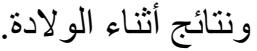

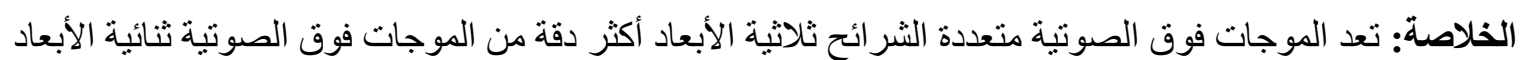

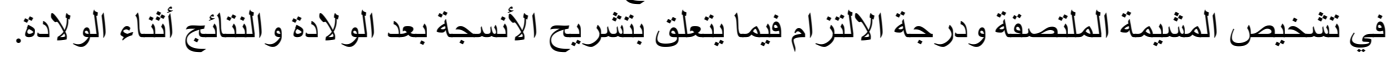

